\title{
Análise do comportamento mecânico de um pavimento reciclado com adição de diferentes agentes estabilizadores
}

\author{
Francisco Dalla Rosa ${ }^{1}$, Fabiano da Silva Jorge ${ }^{2}$, Lélio Antônio Teixeira Brito ${ }^{3}$ e \\ Jorge Augusto Pereira Ceratti ${ }^{4}$
}

\begin{abstract}
Resumo: Este trabalho apresenta um estudo do comportamento mecânico de um pavimento reciclado com adição de dois agentes estabilizadores. O material de estudo, foi coletado junto à BR-116 próximo ao município de Pelotas/RS, é resultado da trituração do revestimento e parte da base. Utilizou-se o cimento Portland e uma emulsão asfáltica como agentes melhoradores de desempenho mecânico da mistura. Foi avaliado o comportamento mecânico da mistura sem os aditivos, e posteriormente com a adição de cada um deles. Os resultados apontaram que a adição de cimento Portland promoveu considerável acréscimo do Módulo de Resiliência (MR), e que esse valor teve um pequeno decrescimento com a adição da emulsão asfáltica. Por outro lado, a adição somente de emulsão asfáltica promoveu pequeno acréscimo do valor do MR triaxial, mostrandose assim uma mistura mais dúctil em relação às misturas que continham cimento Portland.
\end{abstract}

Palavras-chave: Reciclagem de pavimentos; Cimento Portland; Emulsão asfáltica.

Abstract: This paper analyses the mechanical behavior of a Full Depth Reclamation (FDR) pavement recycled with two different stabilized agents. The material from FDR process was collected at the BR-116 roadway, near the city of Pelotas, southern of Brazil. This granular material consists by the asphalt surface and part of the granular base course. Portland cement and asphalt emulsion have been used as stabilizing agents in order to improve the mechanical behavior of the mixture. The experimental study revealed that Portland cement promoted higher values of RM (Resilient Modulus) in comparison to asphalt emulsion plus Portland cement additions. Notwithstanding, mixtures prepared only with asphalt emulsion have presented slight increase on cyclic triaxial RM, resulting, therefore, in a more ductile mix in comparison to those with Portland cement only.

Keywords: Pavement recycling; Portland cement; Asphalt emulsion.

\section{INTRODUÇÃO}

A concepção de estruturas mais robustas para rodovias tem apresentado uma demanda crescente em função dos maiores esforços que o tráfego atual tem solicitado. Dessa forma, cada vez mais tem sido uma necessidade o desenvolvimento de novos materiais, com propriedades mecânicas melhoradas, a fim de promover maior vida útil das rodovias. Esse aspecto fica mais evidente quando se observa a incompatibilidade das estruturas de muitas rodovias brasileiras com relação ao tráfego atuante. Tradicionalmente, as técnicas de restauração de pavimentos flexíveis no Brasil têm se concentrado na reconstrução parcial (fresagem do pavimento antigo) ou total (reconstrução de todas as camadas) da estrutura da via. Nos dois casos citados normalmente são gerados resíduos, eles apresentam relativo potencial de contaminação ambiental caso não sejam corretamente dispostos na natureza.

Em função dessa demanda, a reciclagem de pavimentos flexíveis torna-se uma opção atrativa, uma vez que é

\footnotetext{
1 Francisco Dalla Rosa, Programa de Pós-Graduação em Engenharia Civi e Ambiental, Universidade de Passo Fundo. (f.dallarosa@gmail.com)

2 Fabiano da Silva Jorge, Programa de Pós-Graduação em Engenharia

Civil e Ambiental, Universidade de Passo Fundo.

(eng.fabianojorge@hotmail.com)

${ }^{3}$ Lélio Antônio Teixeira Brito, Laboratório de Pavimentação

Programa de Pós-graduação em Engenharia Civil - Departamento de

Engenharia Civil, Universidade Federal do Rio Grande do Sul.

(leliobrito@gmail.com)

4 Jorge Augusto Pereira Ceratti, Laboratório de Pavimentação

Programa de Pós-graduação em Engenharia Civil - Departamento de

Engenharia Civil, Universidade Federal do Rio Grande do Sul.

(00002327@ufrgs.br)
}

Manuscrito recebido em 06/01/2015 e aprovado para publicação em $17 / 06 / 2015$.

Este artigo é parte de TRANSPORTES v. 23 , n. 2, 2015. ISSN: 2237-1346

(online). DOI: DOI: 10.14295/transportes.v23i2.880 possível incorporar capacidade de suporte ao pavimento antigo, além de reduzir a quantidade de resíduo e diminuir os custos do ciclo de vida de uma rodovia. Cunha (2010), Costa e Pinto (2011) e outros trabalhos apresentaram os benefícios oriundos da utilização da técnica de reciclagem de pavimentos flexíveis. Esses aspectos positivos se concentram principalmente na redução do passivo ambiental, no aumento da capacidade da estrutura e na redução dos custos de manutenção de um pavimento.

Segundo Motta et al. (2002) há informações de que a execução da primeira reciclagem com Concreto Asfáltico Usinado à Quente (CAUQ) ocorreu nos Estados Unidos no ano de 1915. No Brasil, Bernucci et al. (2008) destacam que a reciclagem à frio teve início nos anos 80 , quando chegaram as primeiras recicladoras ao Brasil. No ano de 1985 (COSTA e PINTO, 2011) ocorreu a primeira obra de reciclagem na rodovia Anhanguera, que liga São Paulo a Campinas em pista dupla e com extensão total de 90 quilômetros.

A técnica de reciclagem profunda de pavimentos flexíveis, conhecida também como Full Depth Reclamation (FDR), consiste em triturar o pavimento deteriorado, com adição ou não de ligantes asfálticos ou hidráulicos, além da correção granulométrica quando necessária, e posterior compactação. Essa nova camada de material estabilizado passa a constituir a base de uma nova camada de rolamento que é aplicada posteriormente.

A reciclagem da estrutura antiga de um pavimento reduz sensivelmente os custos da reforma de uma rodovia. Além deste aspecto, torna-se evidente a diminuição do uso de recursos naturais, contribuindo com menores impactos ao meio ambiente. Segundo a Portland Cement Association - PCA (2005), a utilização da reciclagem profunda possibi- 
lita uma redução de 6 vezes o volume de combustível utilizado, quando comparado às técnicas tradicionais de reconstrução de pavimentos degradados.

Da mesma forma, o Departamento Nacional de Infraestrutura de Transportes - DNIT (2006) aponta uma redução de $65 \%$ do consumo energético utilizando-se a técnica da reciclagem da capa asfáltica in situ, em comparação à construção de uma nova camada de revestimento. Além da redução do impacto ambiental também é possível identificar uma redução do custo da manutenção de uma rodovia utilizando a técnica da reciclagem de pavimentos. Trichês e Santos (2011) observaram uma economia de $2,5 \%$ do custo de restauração da SC-303 frente ao uso de técnicas tradicionais.

O desenvolvimento de novos materiais e técnicas para a reciclagem profunda de pavimentos flexíveis à frio tem sido alvo de diferentes estudos em nível nacional (SPECHT et al., 2013; TRICHÊS e SANTOS, 2013 e 2011; BONFIM, 2010; entre outros) e internacional (PUPPALA et al. 2011; FU et al., 2010; KAVUSSI e MODARRES, 2010; NIAZI e JALILI 2008; SULEIMAN, 2002; TAHA et al., 2002; dentre outros). Tais estudos têm focado na identificação do comportamento mecânico de materiais cimentados com adição de diferentes tipos de aglomerantes, tais como o cimento Portland, asfalto espumado, emulsões asfálticas, cal hidratada, entre outros aditivos.

O uso de emulsões asfálticas combinadas com outros ligantes hidráulicos foi o foco de estudo nesse trabalho. Segundo Kavussi e Modarres (2010), a adição desses dois tipos de ligantes tem propiciado melhoras específicas no comportamento das camadas granulares tratadas, tais como redução de problemas com afundamento em trilha de roda e aumento da capacidade de suporte da estrutura do pavimento. Além disso, a reciclagem de pavimentos flexíveis com adição combinada de emulsões asfálticas e cimento Portland (ex. CROTEAU e LEE, 1997) resultam em altas resistências iniciais, menor influência da umidade e melhor desempenho com relação ao afundamento em trilha de roda.

Vários estudos apontam para a importância da rigidez das camadas no dimensionamento de pavimentos flexíveis (PONTE et al. 2014, FRANCO, 2007). Dessa forma, devese levar em consideração que a adição de cimento Portland eleva o Módulo de Resiliência (MR), a resistência à tração/compressão, bem como a resistência às deformações permanentes. Entretanto, misturas levemente cimentadas apresentam comportamento frágil, ao passo que misturas com elevadas quantidades de cimento estão sujeitas a apresentarem trincamento por retração. Por outro lado, o uso de emulsões asfálticas apresenta o benefício de ser utilizada na temperatura ambiente. Tal processo reduz consideravelmente o envelhecimento do ligante, uma vez que não há necessidade de aquecimento do mesmo, resultando numa durabilidade maior da camada tratada.

\section{MATERIAIS E MÉTODOS DE PESQUISA}

\subsection{Local de coleta e características dos materiais}

O local onde foram coletadas as amostras para o estudo de reciclagem situa-se na BR 116 km 528+0,00, próximo à cidade de Pelotas/RS. Tipicamente nessa região, os agregados utilizados nas camadas granulares e revestimento de pavimentos são provenientes da britagem de rochas graníticas. O ligante utilizado na camada existente de concreto asfáltico (CAUQ) possui a classificação CAP 50/70.

Para a obtenção do material a ser reciclado, utilizouse uma Fresadora Wirtgen W1000, a qual triturou uma espessura total de $15 \mathrm{~cm}$, dos quais $5 \mathrm{~cm}$ eram da camada de rolamento e $10 \mathrm{~cm}$ da base de brita graduada conforme apresentado no croqui da Figura 1.

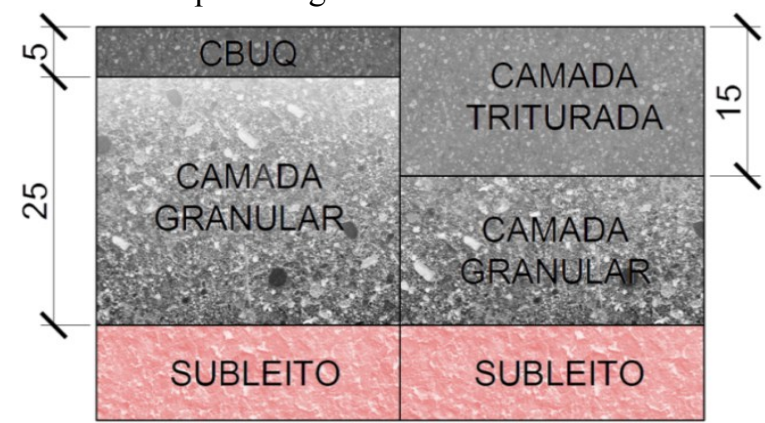

Figura 1. Croqui da estrutura do pavimento de onde foi retirado o material para estudo em laboratório.

Observa-se na Figura 01 que a priori da realização da reciclagem, o pavimento não contava com uma camada de sub-base, possivelmente em função do baixo tráfego local à época de sua concepção. Com a adição da camada triturada como camada reciclada, o pavimento passou a contar com uma camada de base, o que resulta numa melhor distribuição de cargas.

A produção de material fresado para o estudo foi equivalente a $1.000,00 \mathrm{~m}^{2} / \mathrm{dia}$, onde a velocidade de avanço da fresadora foi mínima para manter a mistura uniforme. É importante destacar que as recicladoras podem apresentar produtividades próximas a $10.000,00 \mathrm{~m}^{2} / \mathrm{dia}$, contemplando o processo de trituração, mistura e espalhamento do material reciclado. Na Figura 2 é apresentado o momento da trituração do pavimento e a característica final do material após secagem em laboratório.

A característica do material triturado está diretamente vinculada à profundidade de corte do pavimento e à velocidade da recicladora aplicadas durante o processo de reciclagem. Por ter sido utilizada uma velocidade relativamente baixa da fresadora, nesse estudo não foi realizada a adição de agregado virgem ao material obtido em campo. Ao se observar a análise granulométrica (Figura 3 ) do material triturado pela fresadora, identificou-se que o mesmo se encontra dentro dos limites estabelecidos pela norma DNIT 167/2013-ES (DNIT, 2013), Faixa I, a qual estabelece as especificações para reciclagem profunda de pavimentos com adição de cimento Portland.

Outra motivação para a não adição de materiais virgens diz respeito às questões ambientais envolvidas nas etapas do processo de produção de novos agregados, como a escavação de jazidas e britagem da rocha procedente desses locais. Aliado a esse fato, deve-se também levar em conta a redução dos locais de deposição do rejeito da fresagem, visto que normalmente esses materiais são dispostos em bota-foras.

\subsection{Tipos de ligantes}

Nesse estudo foram utilizados dois tipos de ligantes com o intuito de promover a melhora das propriedades mecânicas da mistura reciclada. Assim, utilizou-se o cimento 


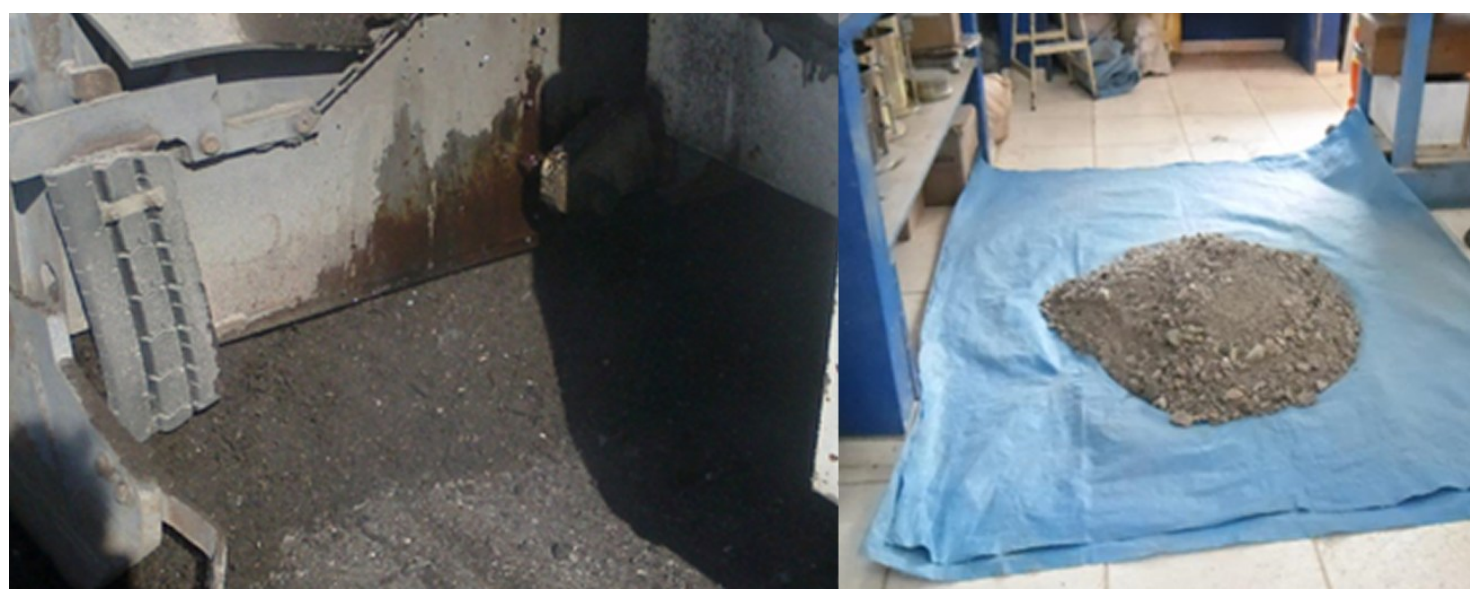

Figura 2. Processamento do fresado em campo e acondicionamento em laboratório

CP-IV como ligante hidráulico e uma emulsão asfáltica produzida por uma empresa nacional como ligante asfáltico. Um breve resumo das características de ambos ligantes é apresentado na Tabela 1.

\subsection{Dosagem das misturas}

Foram concebidos 3 tipos de misturas distintas com o intuito de assimilar os efeitos que a adição da emulsão e a presença do cimento Portland apresentam no comportamento da camada tratada. Assim, as misturas adotadas nessa pesquisa compreendem: contendo somente emulsão; contendo somente cimento Portland; e a combinação dos dois ligantes em uma terceira configuração de dosagem.
A dosagem dos teores ideais da emulsão asfáltica na mistura reciclada foi estabelecida através da metodologia Marshall e também pelo método Proctor modificado. O estudo realizado através da metodologia Marshall viabilizou além da identificação do teor ótimo de emulsão, a verificação das características de estabilidade e fluência das misturas, como apresentadas na Tabela 2.

O teor de água de molhagem ficou definido por experimentação em $6,5 \%$ para a dosagem de material com adição de cimento, em 3,0\% para a dosagem de material com adição de emulsão e em 3,0\% para a dosagem de material com adição combinada de emulsão e cimento.

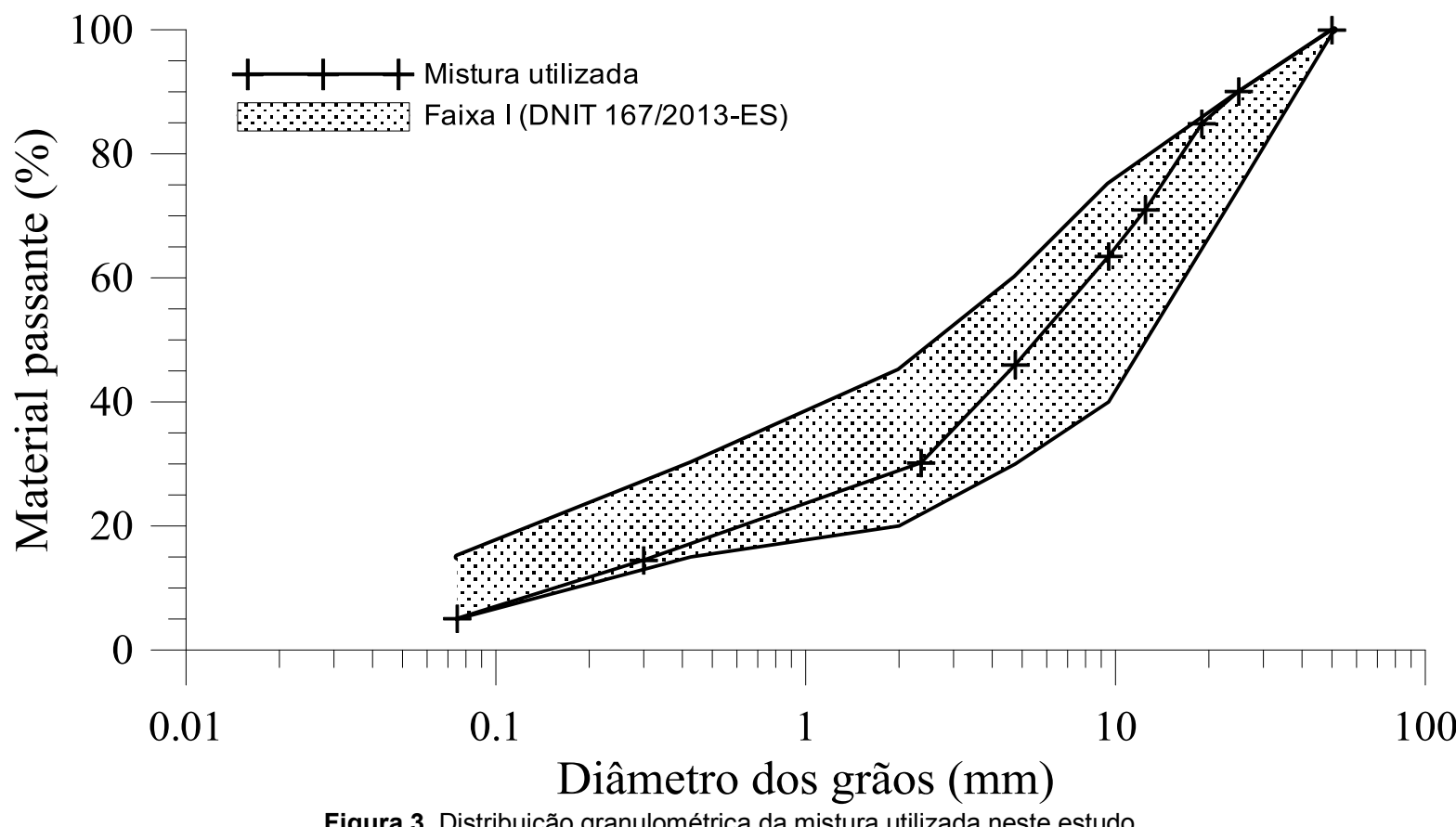

Figura 3. Distribuição granulométrica da mistura utilizada neste estudo.

Tabela 1. Principais características dos ligantes utilizados nesse estudo

\begin{tabular}{llll}
\hline \multirow{2}{*}{ Propriedade avaliada } & \multirow{2}{*}{ Especificação de ensaio } & \multicolumn{2}{l}{ Ligante } \\
\cline { 3 - 4 } & Asfáltico & Hidráulico \\
\hline Viscosidade Saybolt-Furol: SSF a 50 ${ }^{\circ} \mathrm{C}$ & NBR 14491 (ABNT, 2007) & $12 \mathrm{~s}$ & N.A. \\
Destilação do resíduo & NBR 6568 (ABNT, 2005) & $49 \%$ & N.A. \\
Determinação de Finura na Peneira N 200 & NBR 11579 (ABNT, 2012) & N.A. & $3,6 \%$ \\
\hline
\end{tabular}


A partir dos resultados dos ensaios da dosagem Marshall e de compactação Proctor foram estabelecidas as características das misturas de referência para os ensaios de tração indireta, pelo ensaio de compressão diametral. Os ensaios de compressão diametral foram realizados seguindo os critérios propostos pela norma DNIT 136/2010 - ME (DNIT, 2010). Todas as amostras para o ensaio de compressão diametral tiveram diâmetro igual a $100 \mathrm{~mm}$ e altura de $63,5 \mathrm{~mm}$, similares àquelas obtidas a partir da moldagem pelo sistema Marshall.

\subsection{Execução dos ensaios de Módulo de Resiliência (MR)}

Os ensaios de Módulo de Resiliência foram realizados junto ao laboratório de pavimentação (LAPAV) da Universidade Federal do Rio Grande do Sul (Figura 4). Ao todo foram analisadas 36 amostras com os teores ótimos de emulsão, cimento e emulsão + cimento.

Os testes foram divididos em dois grupos distintos, sendo um deles composto por ensaios de compressão axial com amostras confinadas e outro por ensaios de compressão diametral. As amostras que não levaram adição de nenhum dos ligantes, bem como a que continha somente emulsão asfáltica foram submetidas aos ensaios de compressão axial cíclica em diferentes pares de tensões $\left(\sigma_{\mathrm{d}}\right.$ e $\left.\sigma_{\mathrm{r}}\right)$. Tais amostras possuíam diâmetro e altura respectivamente iguais a 75 $\mathrm{mm}$ e $150 \mathrm{~mm}$.

Por outro lado, as amostras que receberam adição de cimento Portland foram conduzidas a ensaios de módulo de resiliência por compressão diametral (Figura 4). Optou-se pelo estudo das propriedades elásticas das misturas que continham cimento Portland, pelo fato que as mesmas tendem a apresentar um comportamento frágil, principalmente quando solicitadas aos esforços de tração. Esse aspecto na maioria das situações de bases estabilizadas com cimentos hidráulicos pode governar a vida útil da camada tratada.

Tais amostras possuíam diâmetro e altura iguais respectivamente a $100 \mathrm{~mm}$ e $63,5 \mathrm{~mm}$ (Similares às dimensões do ensaio Marshall). Todos os ensaios seguiram as recomendações propostas pelas normas NBR 16018 (ABNT, 2011). Os valores de tensão de tração aplicados foram da ordem de $10 \%$ da resistência à tração.

Esse tipo de ensaio também foi realizado para misturas que levaram consigo a adição concomitante de cimento e emulsão, ambas na taxa de $3 \%$ da massa de seca do pavimento reciclado. Todas as amostras com adição de cimento Portland tiveram um tempo de cura mínimo de 28 dias.

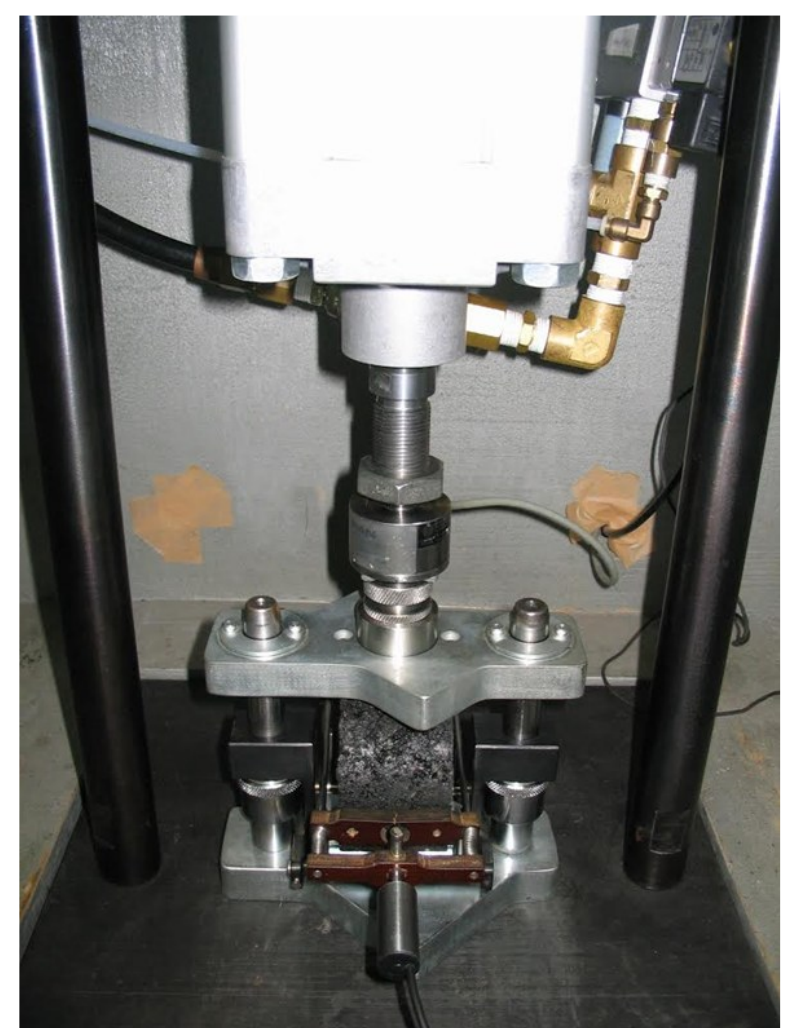

Figura 4. Equipamento utilizado para os ensaios de Módulo de Resiliência por compressão diametral.

Tabela 2. Resumo dos resultados da dosagem Marshall e ensaio de compactação Proctor.

\begin{tabular}{ll|llll}
\hline \multicolumn{2}{c|}{ \% de ligante } & \multicolumn{4}{c}{ Parâmetros identificados } \\
\hline \multirow{2}{*}{ Emulsão } & Cimento & $V v(\%)$ & $\begin{array}{l}\text { Peso especifico } \\
\left(\mathrm{kN} / \mathrm{m}^{3}\right)\end{array}$ & $\begin{array}{l}\text { Estabilidade } \\
(\mathrm{kN})\end{array}$ & Fluência $(\mathrm{mm})$ \\
\hline 3 & 0 & 11,2 & 20,5 & 3,0 & 2,8 \\
0 & 3 & 12,5 & 20,6 & 22,0 & 3,3 \\
3 & 3 & 8,5 & 21,4 & 13,4 & 2,7 \\
\hline
\end{tabular}


Tabela 3. Coeficiente de regressão obtidos a partir do modelo $M R=k_{1} \cdot \theta^{k 2}$

\begin{tabular}{|c|c|c|c|}
\hline \multirow[b]{2}{*}{ Material } & \multicolumn{2}{|c|}{ Coeficientes } & \multirow[b]{2}{*}{ Coeficiente de regressão $\left(R^{2}\right)$} \\
\hline & $k 1$ & $k 2$ & \\
\hline Mistura de referência & 362 & 0,59 & 0,92 \\
\hline Mistura de referência + Emulsão asfáltica & 522 & 0,64 & 0,96 \\
\hline Granito * & 870 & 0,46 & \\
\hline Basalto $01 *$ & 525 & 0,45 & $0,7-1$ \\
\hline Basalto $02 *$ & 635 & 0,64 & \\
\hline
\end{tabular}

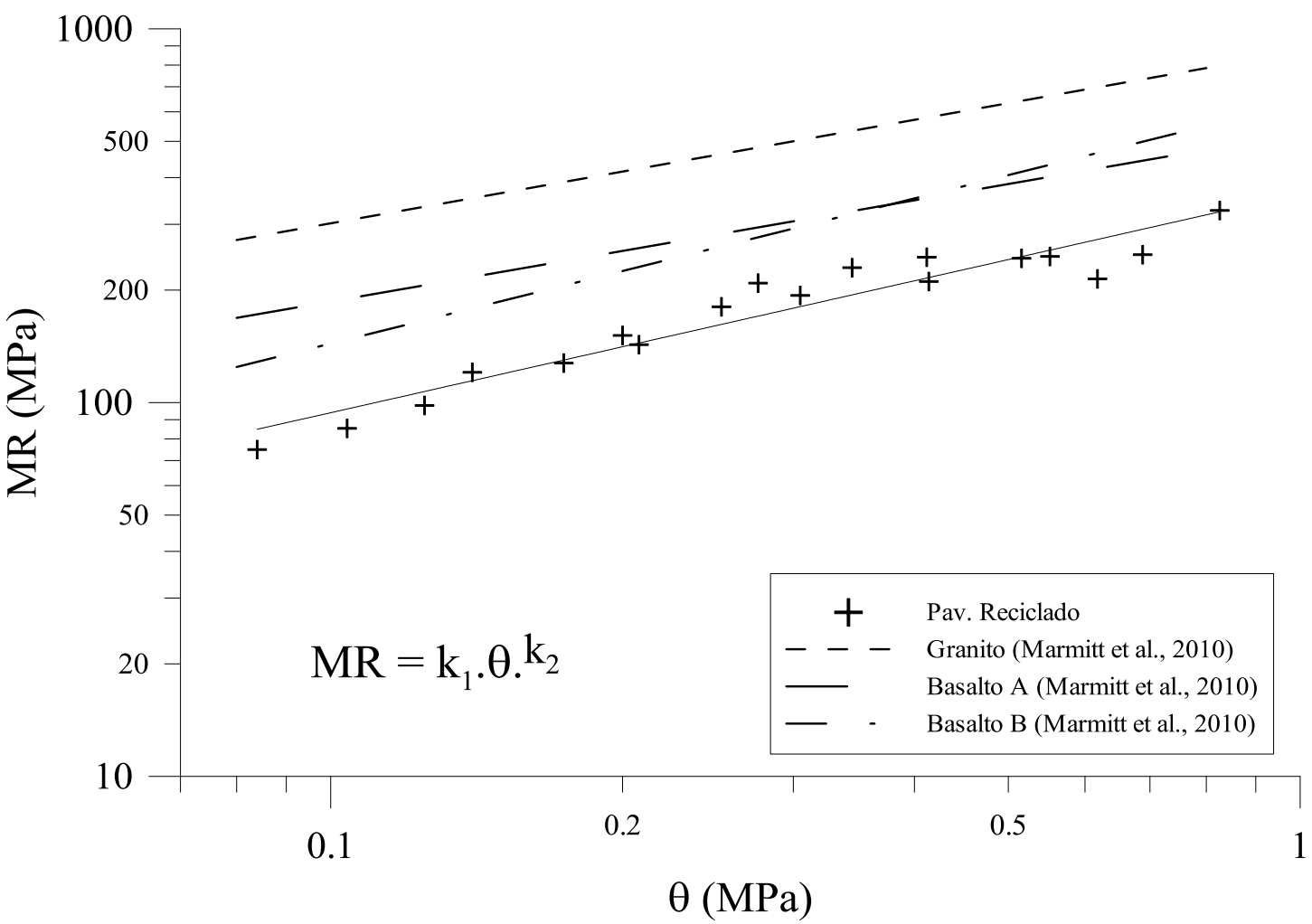

Figura 5. Análise do módulo de resiliência do material sem adição dos ligantes.

\section{ANÁLISE DO COMPORTAMENTO MECÂNICO DAS MISTURAS}

\subsection{Comportamento da mistura não cimentada}

Com o intuito de avaliar o comportamento do material sem cimentação foi conduzido um ensaio de módulo de resiliência sob compressão axial em diferentes níveis de confinamento como apresentado na Figura 5. Ao comparar os resultados obtidos nesse ensaio com os resultados apresentados por Marmitt et al. (2010), identificou-se que a mistura dessa pesquisa apresenta comportamento inferior em baixos níveis de confinamento. Para maiores tensões de confinamento há uma tendência de o comportamento se tornar similar ao obtido para o agregado de granito quando analisado através do modelo proposto, em que $\theta$ é o invariante de tensão e representa a soma das tensões principais $\left(\sigma_{1}+\sigma_{2}+\sigma_{3}\right)$.

Esse fato ocorre em função do esmagamento dos grumos ao longo dos ciclos de carga/descarga, o que promove uma possível densificação da mistura de acordo com o aumento do nível de tensões. Tal aspecto fica evidenciado quando são analisados os valores da Tabela 3, no qual o coeficiente $\mathrm{k}_{2}$ do modelo de comportamento do material se apresenta superior aos encontrados para materiais virgens.

Outro aspecto a ser considerado diz respeito à quebra desses grumos, a qual pode ocorrer em níveis de tensões/deformações menores. Isso possibilitaria um processo de consolidação da camada triturada, resultando assim no surgimento de deformações permanentes em um pavimento reciclado. Essa ideia pode ser corroborada a partir de um estudo apresentado por Niazi e Jalili (2008), ambos observaram que pavimentos reciclados sem aditivos aglutinantes estão mais propícios ao apresentarem problemas com deformações permanentes.

\subsection{Comportamento das misturas com ligante hidráulico e asfáltico}

Observando-se os resultados apresentados na Figura 6 , identifica-se que a adição de emulsão asfáltica promoveu valores de estabilidade Marshall menores, comparando-se com as amostras que continham somente cimento Portland. Porém, em ambos casos é possível identificar uma relação de ganho proporcional da estabilidade Marshall com o aumento do nível de cimento. Já as misturas que continham somente emulsão asfáltica não apresentaram o mesmo comportamento, sendo possível estabelecer um teor ótimo de 

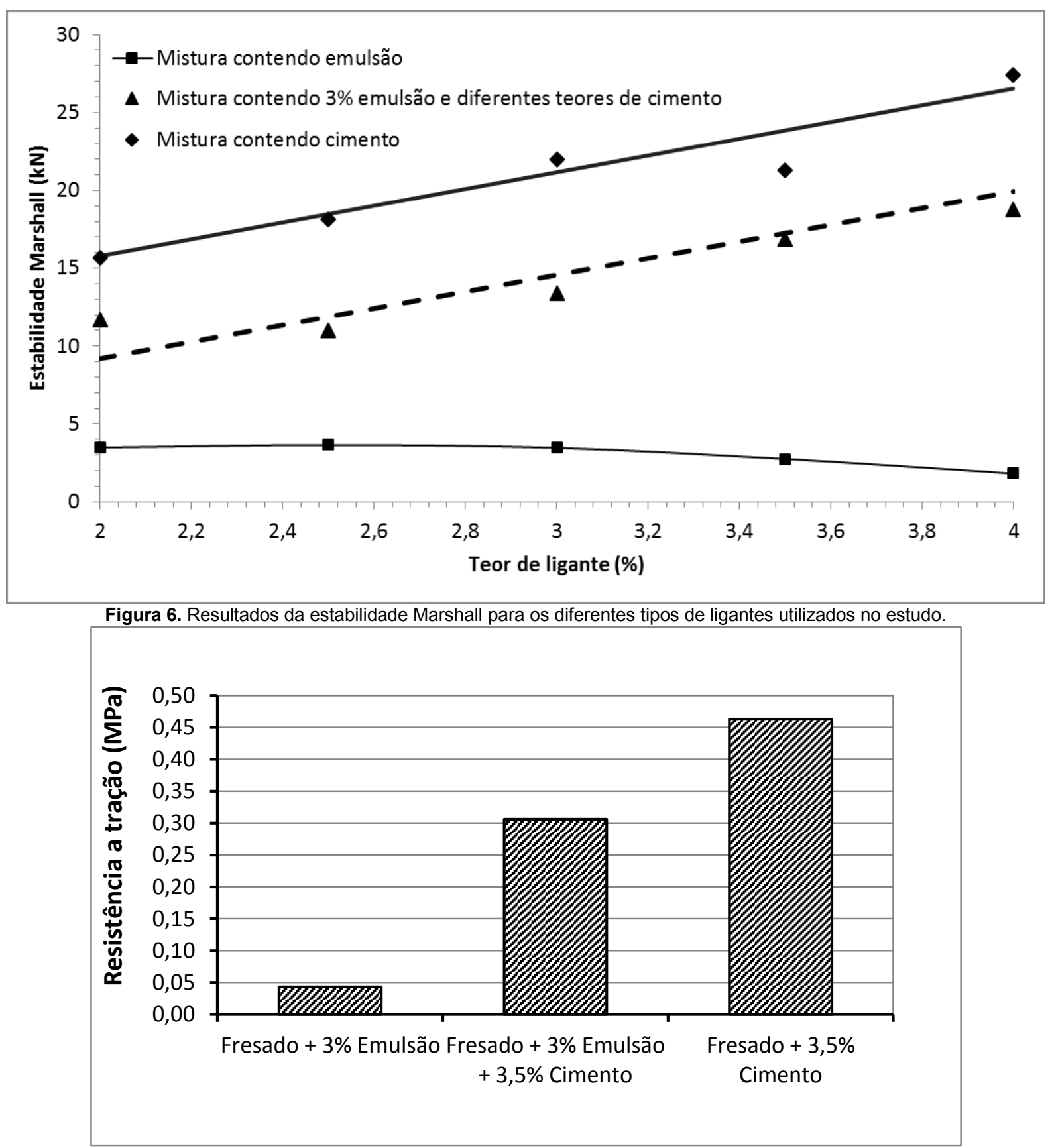

Figura 7. Resultados obtidos a partir dos ensaios de compressão diametral.

emulsão que proporciona um melhor resultado da estabilidade Marshall, tipicamente observado em misturas betuminosas.

Essa tendência de comportamento também foi observada nos ensaios de compressão diametral. A Figura 7 apresenta um resumo dos resultados de compressão diametral e demais parâmetros para as misturas analisadas. Observa-se que as amostras preparadas com adição de cimento Portland apresentaram valores de resistência à tração significativamente maiores em relação às amostras preparadas com adição de emulsão asfáltica. Entretanto, nota-se que o acréscimo da emulsão asfáltica não promoveu considerável queda da resistência à tração, conforme observado nos ensaios de estabilidade Marshall (Figura 6).

Por outro lado, os efeitos da emulsão utilizada ficaram evidentes quando analisado o comportamento da mistura sobre compressão axial cíclica. Na Figura 8 são expostos os resultados do pavimento reciclado com a adição de
$3 \%$ de emulsão asfáltica. É possível identificar uma melhora nas propriedades mecânicas da mistura quando comparada com aquela que não recebeu a adição de emulsão. Tal evolução pode ser observada pelo incremento do valor do módulo de resiliência sob diferentes condições de confinamento, bem como corroborada pelos coeficientes de regressão $\mathrm{k}_{1}$ e $\mathrm{k}_{2}$ apresentados na Tabela 3 .

$\mathrm{Na}$ Figura 9 são apresentados os valores típicos para o módulo de resiliência obtidos para as misturas que continham cimento Portland. Observa-se que as misturas com adição de cimento Portland apresentaram valores de MR bastante elevados. A adição concomitante de emulsão e cimento Portland resultou num valor de MR ligeiramente inferior comparada à mistura que só continha cimento.

Entretanto, os valores encontrados de MR para as misturas com cimento Portland são indicativos de um material com elevada rigidez e com possíveis problemas com 


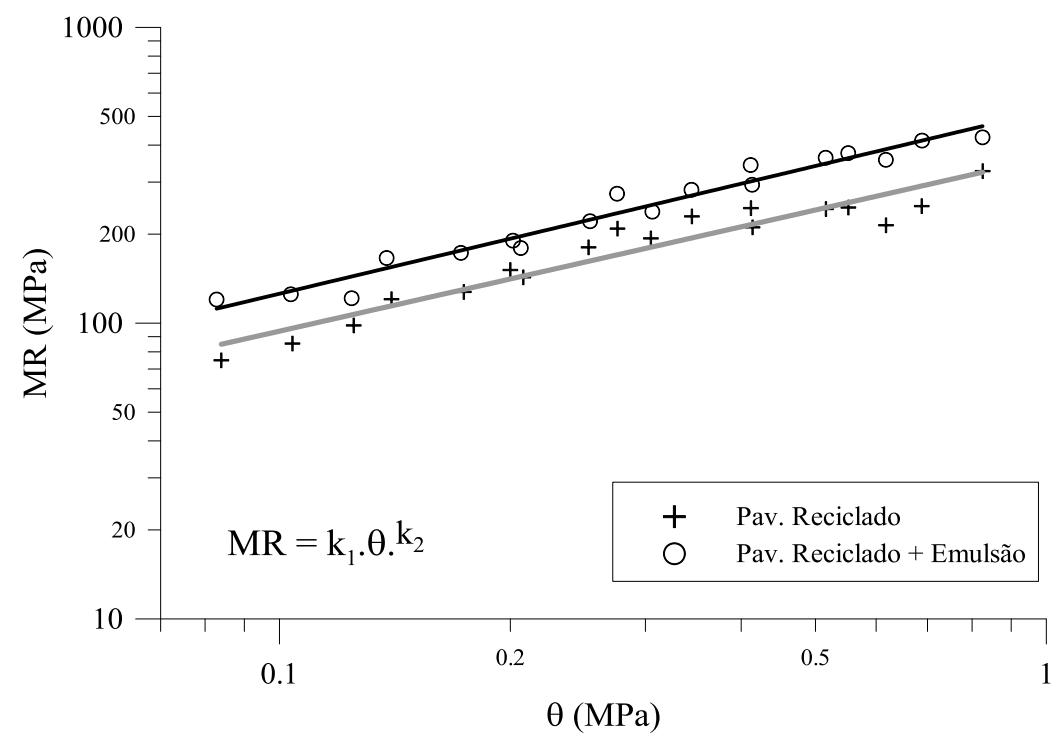

Figura 8. Efeito da adição da emulsão asfáltica no comportamento resiliente da mistura.

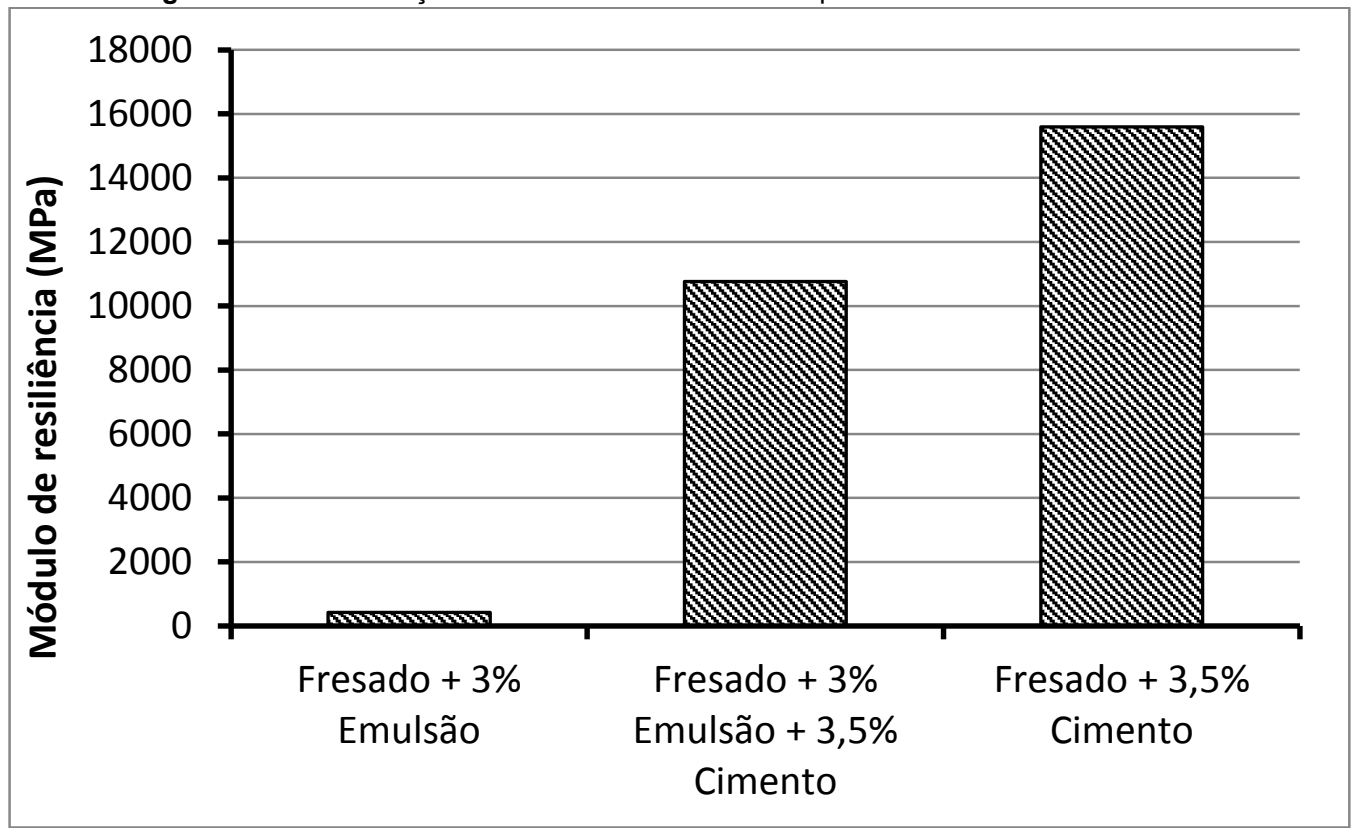

Figura 9. Resultados de módulo de resiliência para as misturas adotadas neste estudo.

relação a sua fragilidade. Tais valores de MR são relativamente superiores a outros estudos apresentados na literatura (PUPPALA et al. 2011; TAHA et al., 2002), onde as misturas dessas pesquisas obtiveram valores de MR entre 590 $\mathrm{MPa}$ e $3700 \mathrm{MPa}$. Deve-se também considerar que os ensaios de MR foram realizados com tensões relativamente baixas, que correspondem entre 15 e $30 \%$ da resistência à tração das misturas. Tais níveis de tensões resultam em valores de deformação relativamente baixos, observando-se assim uma maior dificuldade na interpretação dos resultados.

A questão da fragilidade de pavimentos reciclados com adição de cimento Portland e emulsão asfáltica foi abordada por Kavussi e Modarres (2010). Eles identificaram que a adição de ligante hidráulico permitiu uma alteração da curva de fadiga de misturas testadas a $25^{\circ} \mathrm{C}$. Segundo os autores, tal fato pode indicar uma maior fragilidade das misturas que continham cimento Portland frente às misturas que continham a combinação de emulsão e cimento.

Outro indicativo de acréscimo da rigidez diz respeito aos elevados valores da relação entre MR e RT. Observa-se a partir dos resultados apresentados nas Figuras 7 e 9 que a relação entre a rigidez e a resistência das misturas foi de
33678 e 35160 respectivamente para as misturas que continham cimento + emulsão e somente cimento Portland. Esse fato indica que mesmo com a adição da emulsão asfáltica juntamente com o cimento Portland houve uma pequena redução dos valores de MR.

Importante avaliar que uma vez que o aumento na rigidez tenha sido consideravelmente mais expressivo do que o aumento na resistência para as misturas com material fresado mais emulsão e cimento, há sugestão de que o trincamento por fadiga possa representar um problema nessas camadas. Isto remete à necessidade de investigações adicionais sobre esse comportamento em estudos futuros.

Como forma de avaliar preliminarmente esse comportamento, foi verificada a energia dissipada durante a realização dos ensaios de Módulo de Resiliência para as misturas testadas. Brito et al. (2008) demonstraram que a verificação da energia dissipada em ensaios diametrais pode ser considerada como indicador da performance esperada das misturas asfálticas. Nesse sentido, ainda que incipiente a avaliação, a Figura 10 mostra um maior consumo de energia (através da área do laço histérico - tensão vs. deformação) durante a realização do ensaio para níveis de tensões semelhantes. 


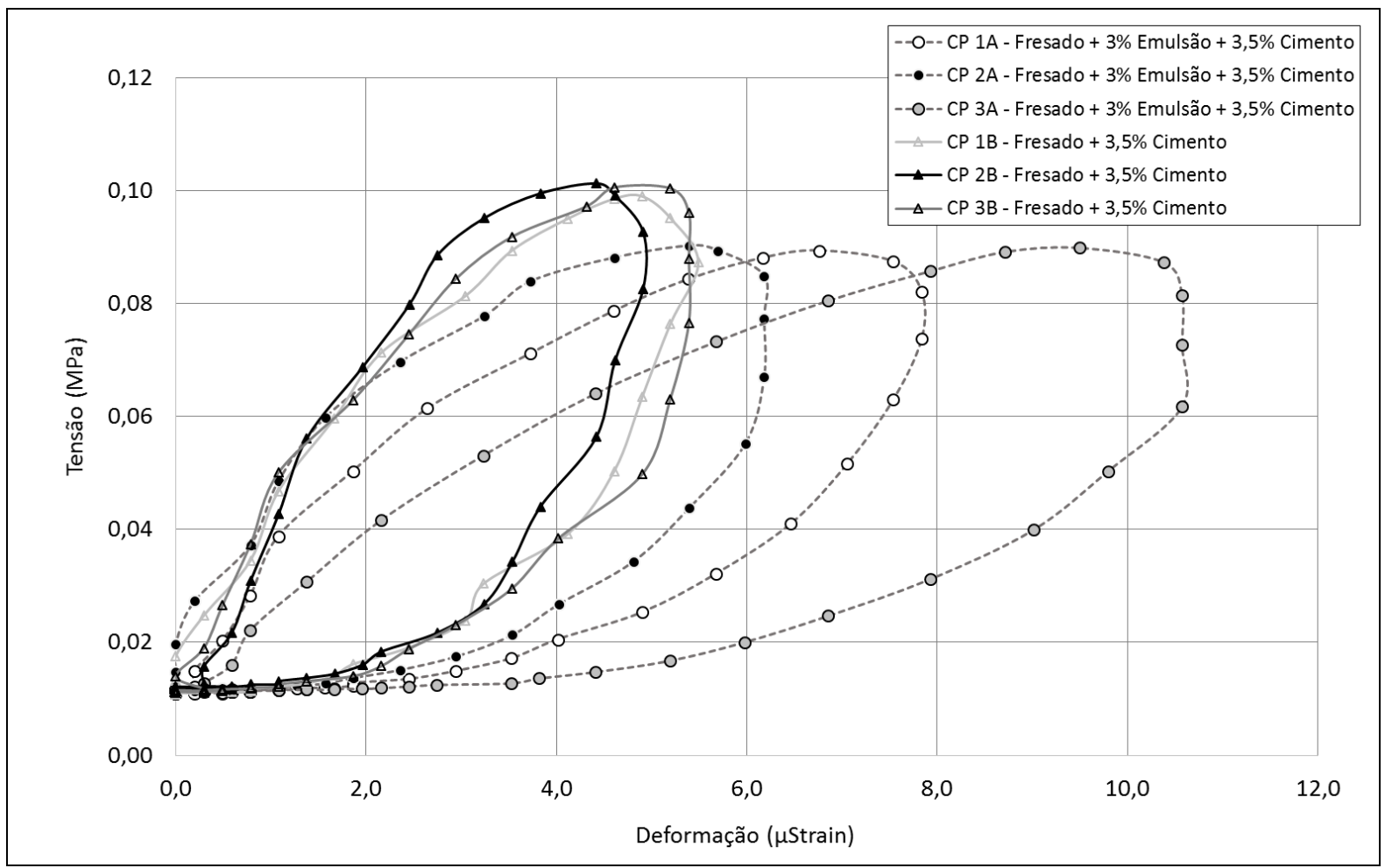

Figura 10. Gráfico Tensão-deformação obtido durante os ensaios de Módulo de Resiliência.

A análise desses dados mostra um maior consumo de energia quando da adição de emulsão + cimento ao resíduo. Esse incremento associado à queda dos valores de resistência (cerca de $35 \%$ menos resistência para as misturas com adição de emulsão e cimento, em relação àquela com cimento apenas) implica num melhor comportamento da mistura com adição de cimento.

\section{CONCLUSÕES}

Nesse trabalho apresentou-se um intensivo programa experimental vinculado ao estudo do comportamento mecânico de pavimentos reciclados com adição de cimento Portland e de uma emulsão asfáltica. Num primeiro momento, foi realizada a avaliação do comportamento das misturas sem adição dos ligantes propostos no estudo, a qual serviu como base para as análises realizadas no estudo. Observouse que misturas sem aditivos apresentaram um comportamento inferior em relação aos materiais virgens disponíveis na região de coleta dos materiais. Entretanto, tal comportamento está associado à possível quebra de grumos, normalmente presentes no material fresado durante o processo de carregamento dinâmico.

A adição dos diferentes tipos de ligantes (asfáltico e hidráulico) promoveram comportamentos distintos do ponto de vista de resistência e deformabilidade. A adição de emulsão asfáltica promoveu uma melhora do comportamento das misturas solicitadas à compressão axial cíclica, observadas a partir da análise do invariante de tensões em relação aos valores de MR. É possível inferir que a adição da emulsão asfáltica irá resultar num material menos suscetível a deformações permanentes. Por outro lado, a adição de cimento Portland resultou valores de resistência à tração relativamente elevados para os níveis de cimentação propostos no estudo. A análise da deformabilidade das misturas indicou valores de MR tipicamente elevados, resultando em relações de MR/RT superiores a 35 mil, o que demandará numa análise mecanística mais criteriosa durante a fase de projeto, em decorrência da possível fragilidade da camada cimentada. Entretanto, deve-se levar em conta que o nível de tensões utilizado para tais misturas foi relativamente baixo, resultando em deformações pequenas e de difícil interpretação.

Quando combinados, ambos os ligantes numa mesma mistura, observou-se uma queda da RT de 35\% do valor em comparação às misturas que continham somente cimento Portland. Da mesma forma, os valores de MR obtidos resultaram numa queda de cerca de $32 \%$ do valor obtido para as misturas que continham somente cimento, resultando numa relação MR/RT superior a 33 mil. Apesar da redução dos parâmetros de RT e MR para as misturas que continham os dois tipos de ligantes, ressalta-se a importância da aplicação de uma mistura como essa em campo. Nesse caso, a matriz pétrea recebe inicialmente reforço oriundo da emulsão asfáltica o que viabiliza a liberação ao tráfego pouco tempo após a execução. Já o cimento Portland confere à camada uma maior capacidade de suporte num prazo relativamente maior.

Além disso, os resultados da análise dos laços histéricos de tensão vs. deformação, demonstram que amostras que continham cimento + emulsão podem apresentar um comportamento de fadiga melhor frente às misturas que continham somente cimento. Contudo, a confirmação dessa hipótese é condicionada ao estudo mais aprofundado do comportamento dessas misturas em laboratório e em trechos experimentais, o que resultará numa avaliação mais precisa do seu desenvolvimento.

\section{AGRADECIMENTOS}

Os autores agradecem o apoio financeiro concedido pelo $\mathrm{CNPq}$, através do projeto Edital Universal número 477775/2011-0, bem como, a SBS Engenharia e Betunel 
Asfaltos pelo fornecimento dos materiais para o estudo, e as equipes técnicas do LAPAV-UFRGS e LABINFRA-UPF.

\section{REFERÊNCIAS}

ABNT. Associação Brasileira de Normas Técnicas. NBR 11579. Cimento Portland - Determinação do índice de finura por meio da peneira $75 \mu \mathrm{m}$. Rio de Janeiro: Associação Brasileira de Normas Técnicas, 2012, p. 4.

ABNT. Associação Brasileira de Normas Técnicas. NBR 16018. Misturas asfálticas - Determinação da rigidez por compressão diametral sob carga repetida. Rio de Janeiro: Associação Brasileira de Normas Técnicas, 2011, p. 12.

ABNT. Associação Brasileira de Normas Técnicas. NBR 14491. Emulsões asfálticas - Determinação da viscosidade Saybolt Furol. Rio de Janeiro: Associação Brasileira de Normas Técnicas, 2007, p. 8.

ABNT. Associação Brasileira de Normas Técnicas. NBR 6568. Emulsões asfálticas - Determinação do resíduo de destilação. Rio de Janeiro: Associação Brasileira de Normas Técnicas, 2005, p. 5 .

Bernucci, L. B. et al. Pavimentação asfáltica: formação básica para engenheiros. Rio de Janeiro, 2008. Petrobrás: ABEDA. p. 504.

Bonfim, V. Fresagem de pavimentos asfálticos. São Paulo: Ed. Exceção, 3.ed, 2010, p.127.

Brito, L. A. T.; Ceratti, J. A. P.; Victorino, D. R. Indicadores do Desempenho de Misturas Asfálticas Determinados Através do Ensaio de Compressão Diametral. Revista Transportes. v. 16, n. 1, p.36-44, 2008. DOI: dx.doi.org/10.14295/transportes.v.16i1.10

Costa, C.; Pinto, S. O uso de reciclagem de pavimentos como alternativa para o desenvolvimento sustentável em obras rodoviárias no Brasil. São Paulo: Revista Engenharia, 602.ed, 2011. p. 96-102.

Croteau, J. M.; Lee, S. Q. S. Cold In-Place Recycling: Performance And Practices. In: XIIIth IRF World Meeting. Toronto/ Canada, 1997. p. 13. Disponível em: library.tacatc.ca/proceed ings/1997/08_0519.pdf> Acesso em (30/06/2015).

Cunha, C. M. Reciclagem de Pavimentos Rodoviários Flexiveis Diferentes Tipos de Reciclagem. Dissertação (Mestrado) Instituto Superior de Engenharia de Lisboa: Departamento de Engenharia Civil, 2010. p.110.

BRASIL. Departamento Nacional de Infraestrutura de Transportes. DNIT IPR - 720/06. Manual de restauração de pavimentos asfálticos. Rio de Janeiro, 2.ed, 2006, p. 313. Disponível em:

www1.dnit.gov.br/ipr_new/..\%5Carquivos_internet $\% 5 \mathrm{Cipr} \% 5 \mathrm{Ci}$ pr_new\%5Cmanuais\%5CManual_de_Restauracao.pdf $>$ Acesso em $(30 / 06 / 15)$.

. DNIT 167/2013-ES. Pavimentação - Reciclagem profunda de pavimentos "in situ" com adição de cimento Portland - Especificação de Serviço, 2013, p.11. Disponível em: ipr.dnit.gov.br/normas/DNIT167_2013_ES.pdf> Acesso em: (30/06/2015).

. DNIT 136/2010-ME. Pavimentação asfáltica Misturas asfálticas - Determinação da resistência à tração por compressão diametral - Método de ensaio, 2010, p. 6. Disponível em: ipr.dnit.gov.br/normas/DNIT136 2010_ME.pdf> Acesso em $(30 / 06 / 15)$.

Fu, P.; Jones, D.; Harvey, J. T. The effects of asphalt binder and granular material characteristics on foamed asphalt mix strength. Construction and Building Materials. n. 25, 2011. p. 1093-1101. DOI: dx.doi.org/10.1016/j.conbuildmat.2010.06.067

Franco, F. A. C. P. Método de dimensionamento mecanísticoempírico de pavimentos asfálticos - SisPav. Tese (Doutorado) Universidade Federal do Rio de Janeiro, Rio de Janeiro, 2007. Disponível em: www.p.coc.ufrj.br/teses/doutorado/geotecnia/2007/Teses/FRAN CO_FACP_07_t_D_geo.pdf $>$ Acesso em (30/06/2015).

Kavussi, A.; Modarres, A. Laboratory fatigue models for recycled mixes with bitumen emulsion and cement. Construction and Building Materials. 2010, n. 24, p. 1920-1927. DOI: dx.doi.org/10.1016/j.conbuildmat.2010.04.009

Marmitt, H. M.; Casagrande, M. D. T.; Ceratti, J. A. P. Caracterização de propriedades resilientes de três britas graduadas utilizadas em pavimentos no sul do Brasil. Teoria e Prática na Engenharia Civil, 2010, n. 15, p.63-69. Disponível em: www.editoradunas.com.br/revistatpec/Art7_N15.pdf> Acesso em (30/06/2015)

Motta, L. M. et al. In: $16^{\circ}$ Encontro de Asfalto do Instituto Brasileiro de Petróleo. Trecho de reciclagem a frio na BR-393Avaliação após 8 anos da implantação. IBP03102, Anais. Rio de Janeiro, 2002.

Niazi, Y; Jalill. M. Effect of Portland cement and lime additives on properties of cold in-place recycled mixtures with asphalt emulsion. Construction and Building Materials, 2009, n. 23, p. 1338-1343. DOI: dx.doi.org/10.1016/j.conbuildmat.2008 .07 .020

PCA - Portland Cement Association. Full-Depth Reclamation: Recycling roads save money and natural resources, 2005. p.6. Disponível em: <http://www.roadrecycling.org/SR995.PDF> Acesso em (30/06/2015)

Ponte, R. S.; Branco, V. T. F. C.; Holanda, A. S.; SoareS, J. B. Avaliação de diferentes metodologias para obtenção do Módulo de Resiliência de misturas asfálticas. Revista Transportes. v. 22, n. 2, 2014. p. 85-94. DOI:

dx.doi.org/10.14295/transportes.v22i2.792

Puppala, A. J.; Hoyos, L. R.; Potturi, A. K. Resilient Moduli Response of Moderately Cement-Treated Reclaimed Asphalt Pavement Aggregates. Journal of Materials in Civil Engineering - ASCE. v. 23, n. 7, 2011. p. 990-998. DOI: dx.doi.org/10.1061/(ASCE)MT.1943-5533.0000268

Specht, L. P.; Pires, G. M.; Vitorello, T.; Hirsh, F.; Cronst, F.; Bergmann, E.; Tiefensee, M. D. Utilização de material fresado como camada de pavimento: estudo laboratorial e aplicação em campo. In: $42^{a}$ Reunião Anual de Pavimentação. Rio de Janeiro: ABPv, 2013. 12 p.

Suleiman, N. A State-of-the-Art Review of Cold in-Place Recycling of Asphalt Pavements in the Northern Plains Region. Final Report. FHWA, 2002. 102 p. Disponível em: www.dot.nd.gov/divisions/materials/research_project/und 0203final.pdf. Acesso em (30/06/2015).

Taha, R.; AI-Harthy, A.; Ai-ShamsI, K.; Ai-Zubeidi, M. Cement Stabilization of Reclaimed Asphalt Pavement Aggregate for Road Bases and Subbases. Journal of Materials in Civil 
Engineering - ASCE. v. 14, n. 3, 2002. p. 239-245. DOI:

dx.doi.org/10.1061/(ASCE)0899-1561(2002)14:3(239)

Trichês, G.; Santos, A. Desempenho da Reciclagem Com Adição de Cimento da Rodovia SC 150. In: 42 RAP, 2013, Gramado. In $42^{a}$ Reunião Anual de Pavimentação, 2013, Rio de Janeiro: ABP v. 12.

- Avaliação do Desempenho da Reciclagem do Pavimento da Rodovia SC 303. In. $7^{\circ}$ Congresso Brasileiro de Rodovias e Concessões, 2011, Foz do Iguaçu. p.15. 